\title{
Reassessing Aptitude: Introduction to a Special Issue in Honor of Richard E. Snow
}

\section{Patrick C. Kyllonen \& Susanne P. Lajoie}

To cite this article: Patrick C. Kyllonen \& Susanne P. Lajoie (2003) Reassessing Aptitude: Introduction to a Special Issue in Honor of Richard E. Snow, Educational Psychologist, 38:2, 79-83, DOI: $10.1207 /$ S15326985EP3802 2

To link to this article: https://doi.org/10.1207/S15326985EP3802_2

曲 Published online: 08 Jun 2010.

Submit your article to this journal

Џll Article views: 114

Q View related articles ¿

4 Citing articles: 8 View citing articles ¿ 


\title{
Reassessing Aptitude: Introduction to a Special Issue in Honor of Richard E. Snow
}

\author{
Patrick C. Kyllonen \\ Educational Testing Service \\ Princeton, NJ \\ Susanne P. Lajoie \\ Department of Educational and Counseling Psychology \\ McGill University
}

\begin{abstract}
Richard Snow's research influenced many students and colleagues, both directly through his findings and indirectly by inspiring others to carry on the work. A cross-section of his influence is represented in the articles presented in this special issue. Snow was guided by a respect for empirical, quantitative approaches, applications, and a concern for large issues. We present several themes in his work, including the importance of multivariate considerations of individual differences, adapting instruction to individual learners, a process understanding of aptitude, and an enlarged role for spatial ability.
\end{abstract}

Richard Snow made many direct contributions to the fields of cognitive, differential, instructional, educational, and what he liked to call "cognitive differential" psychology. But perhaps his greatest contributions were indirect-through his students, colleagues, and inspirees. Some of those contributions have been captured in the recently published Remaking the Concept of Aptitude: Extending the Legacy of Richard E. Snow (Corno et al., 2002). This was a unique, joint effort by the Stanford Aptitude Seminar to complete, posthumously, a project of Snow's several decades in the making. The project combined two themes: a theory of individual differences in ability and personality and a conceptualization of aptitude that emphasizes the transactions between these characteristics of persons and the affordances of particular situations. D. F. Lohman (personal communication, October 21, 2002), one of the coauthors of this work, kindly summarized the thesis as follows:

Persons come to the situation with a repertoire of propensities, only some of which are potentially useful for goal attainment. The situation, on the other hand, makes some actions more likely or useful than others. But which propensities

Requests for reprints should be sent to Patrick C. Kyllonen, Educational Testing Service, MS 16-R, Rosedale Road, Princeton, NJ 08541. E-mail: pkyllonen@ets.org function as aptitudes (or inaptitudes) depend ultimately on the transactions that occur on a moment by moment basis as the person perceives, acts, reacts, and transforms both by situation and self.

The result of Corno et al.'s (2002) efforts is a unique treatise that captures and substantively builds on Richard Snow's views of human abilities and their relation to learning via the situations and conditions of learning.

Snow's legacy stretched beyond the Aptitude Seminar. He articulated and summarized the state of European psychological science as the liaison scientist for psychology in Europe and the Middle East for the U.S. Office of Naval Research in London from 1983 to 1985 . He was instrumental in the founding of the European Association for Research on Learning and Instruction (EARLI). He was a recipient of numerous awards and recognitions, such as the American Psychological Association's E. L. Thorndike Award for Distinguished Psychological Contributions to Education, Educational Testing Service's Distinguished Service to Measurement Award, and election to the National Academy of Education. We cannot in this small collection even begin to summarize all of these contributions. Rather, the purpose of this special issue is to present research inspired by Snow and by so doing provide a more comprehensive account of his influence. 


\section{THEMES}

Several themes run through the articles contained here, reflecting key issues in Snow's work. A primary theme is the importance of the role of aptitude in instruction, with aptitude broadly defined to accommodate cognitive, affective, and conative characteristics. Most aptitude research concerns cognitive abilities, of course, such as reasoning, verbal ability, spatial ability, and the like. But Snow conceived of aptitude as any personal characteristic that affected one's learning-going so far at times as to include attitudes, talents, or even physical characteristics. Throughout a period in which mentioning individual differences had become politically unfashionable, he played a consistent and relentless role. Whether speaking to cognitive psychologists or to educators, he reminded his audience of the magnitude and importance of differences among people. To illustrate his point, he sometimes showed pictures from anatomy texts illustrating variation in human hearts; at other times he presented eye-movement plots from his own research, revealing the radically different pathways test examinees would take in solving multiple-choice test items. The point was that our differences are not always detrimental, but rather they could lead to correct but unique solutions to problems.

A second theme was Snow's strongly held belief that instruction ought to be adapted to accommodate the aptitudes of individual learners, in a formulation known as aptitude-treatment interactions or ATIs. This work, of course, was done in collaboration with the late Lee Cronbach. Together, they conducted seminal research on the topic, reanalyzed many published reports, and reported their findings in a classic volume (Cronbach \& Snow, 1977) and in related articles (Cronbach, 1975; Snow, 1977).

A third theme is that of aptitude processes, or the notion that aptitude ought to be investigated and understood not simply as a summative test score but also as a dynamic process. Snow believed that only as a result of a detailed investigation of performance on those cognitive tasks known as aptitude tests, would aptitude be understood. And only with such understanding would it be possible to reliably design instructional treatments to accommodate student aptitudes.

Finally, a theme in Snow's research was a special interest in the role of spatial ability, which he saw as an important but understudied aptitude. Snow was well known to his students for developing elaborate, complex three-dimensional graphs, by hand, of course, not only to plot multivariate data but also to illustrate multifarious concepts. Snow attributed his students' common failure to comprehend his graphs and diagrams to a systematic bias in the educational system to reward verbal production and comprehension at the expense of spatial understanding.

Across the articles, and throughout Snow's career, there are additional, overarching themes. One is a reliance on empiricism. Snow was a data person. Nothing interested him so much as examining data—-working with it, touching it, twist- ing and turning it, exploring it, reanalyzing it, replotting it. Data represented a mystery to be solved, not merely a proposition to be tested. Another was the idea that learning and education were complex. He was not only skeptical of but downright hostile toward the idea that complex cognition could be captured by a handful of rules or that a simple cognitive task would reflect much of importance in real-world learning and performance. Although he was excited about the potential of technology for adaptive instruction and dynamic forms of assessment, computer simulation models, as elegant as they were, did not excite him. He thought there was far more to learning and performance than input-output relations. He talked about the importance of will, determination, cognitive flexibility, fluidity, and even playfulness. In the end, his own research on some of these ideas was speculative, and unfortunately he did not have time to test them empirically. But their voicing stood as a reminder that even during the heady days of seemingly rapid advances in our understanding of human cognition, we still have intriguing questions that have yet to be addressed.

For this special issue, we asked active researchers who we knew to be inspired by Richard Snow and his research themes to participate in this project. The sample presented here by no means is exhaustive but does touch on some of the key themes. Phillip Ackerman (2003) has been a long-term follower of the Snow research group and in recent years has revived Snow's idea of aptitude complexes and transformed it into his notion of trait complexes. Valerie Shute (Shute \& Towle, 2003) was, and is, an enthusiastic bearer of the ATI flame, expanding on notions of micro- and macroadaptation and bringing aptitude-treatment interactions into the world of electronic learning. Dan Woltz (2003), a student of Snow's in the mid-1980s, picked up on the process analysis theme and has developed a long-term research program on the processing underpinnings of learning. Susanne Lajoie (2003), also a student of Snow's in the mid-1980s, applied process analyses to spatial problem-solving tasks and developed a computer-based tutoring system to help train students in orthographic projection, an important skill in mechanical engineering and architecture. Currently, she applies cognitive theories to the design of computer-based learning environments for classroom and real-world applications. Snow was aware of all these activities and was enthusiastically supportive of them. We are confident that he would have been pleased with this collection of contributions.

\section{OVERVIEW OF ARTICLES}

Each of the articles picks up on one of the themes identified-trait complexes, ATIs, process analyses, and spatial ability. All articles have a strong quantitative, empirical foundation but are nested within appropriately complex theoretical frameworks. 


\section{Ackerman Article}

Ackerman's article (2003) deals with Snow's concept of aptitude complexes, which inspired Ackerman's more recent work on trait complexes. An aptitude or trait complex is a set or configuration of aptitude variables. The aptitude complex proposal is that it is these sets of variables, which interact in some fashion, that ought to be studied as a whole, rather than the single variables that make up the set. Snow's aptitude and Ackerman's trait complexes are not the same, but the fundamental idea underlying both is similar. Both presume that single-predictor, single-outcome studies are not fruitful approaches for understanding the relation between aptitude and instructional outcomes.

Ackerman (2003) traces the history and evolution of Snow's thinking about aptitude complexes. He begins with the theoretical foundation of Snow's dissertation research, which addressed the question of whether aptitude variables interacted with each other to affect learning outcomes. He then discusses the realization of these ideas in doctoral theses by two of his students-Ann Porteus and Penelope Peterson-who found evidence for such interactions between cognitive ability and anxiety in affecting the usefulness of instructional support in learning. The review discusses several other studies that contributed to Snow's formulation of several candidate trait complexes. These were (a) fluid and crystallized ability, (b) crystallized and spatial ability, (c) a pair of motivation factors, (d) motivation and anxiety, and (e) crystallized ability and anxiety.

Ackerman's (2003) historical development of Snow's research on aptitude complexes provides us with insights into the roots of Ackerman's current notions on trait complexes. Ackerman builds on Snow's research, but there are differences. One is substantive. Against Snow's proposed five aptitude complexes, Ackerman proposes four, which emerge fairly directly from factor analyses of ability, interest, and personality data. These are the trait complexes of (a) social, (b) clerical-convention, (c) science-mathematics, and (d) intellectual-cultural.

Another difference is more conceptual-it goes directly to the meaning of complex. When Snow referred to an aptitude complex he was referring specifically to an interaction between factors. His idea was that the interaction term (e.g., anxiety by verbal ability) might account for variance in treatment outcomes independently of variance accounted for by the components (e.g., anxiety, ability) that make up the interaction. Now, as Corno et al. pointed out (2002, p. 117), finding an interaction is worthy of discussion in its own right, regardless of interacting with treatment. Still, Snow's concern was with predicting treatment outcomes.

In contrast, Ackerman (2003) does not treat complexes as interactions. Rather he refers to the "commonality" among variables in a complex, and he refers to such variables as serving as an "amalgamation." That is, for Ackerman, commonality is the essence of his use of trait complex-a complex then is simply a collection of variables that go together. This contrasts with "interaction," which was the essence of Snow's use. For variables to form a complex in Ackerman's scheme, they must intercorrelate. For variables to form a complex in Snow's scheme, it is not necessary that the variables intercorrelate, only that they interact in affecting outcomes. What this means is that the two proposals ought not to be considered competing hypotheses but, rather, may be complementary. Perhaps the different schemes may be most useful for different purposes. Snow's complexes may be most useful for the applied purpose of predicting treatment outcomes; Ackerman's complexes may be most useful for the more theoretical pursuit of studying coherences among personal characteristics.

\section{Shute and Towle Article}

Like Ackerman (2003), Shute and Towle (2003) see Snow's influence in understanding learning through a number of factors-knowledge, skills, abilities, personality, styles, interests, and the like. However, Shute and Towle focus on the instructional treatment portion of the ATI equation. According to Shute and Towle, Snow was correct in believing that for instruction to be optimal it should adapt to learner characteristics. Unfortunately, they state that the "ATI idea got a bad name due to the noisy conditions inherent in the early classroom studies that investigated the phenomenon." With computers, Shute and Towle are convinced that ATIs will be found and replicated.

In fact, Shute has identified many ATIs in her work. In the first study, Shute and Towle (2003) describe an ATI with two instructional treatments for teaching electricity concepts: rule application, where the computer provides the rule to the student; and rule induction, where the student has to discover the rule from examples. In the computer learning environment, students were presented problems to solve but had the option of exploring electricity concepts by running simulations. One of the variables measured was the proportion of time students spent exploring the computer environment, reading definitions of electricity concepts, and manipulating values on an electrical circuit and observing results. Some learners spend a lot of time exploring the computer environment, whereas others tend to pragmatically go right to the problems, spending minimal amounts of time playing with the electricity simulation. Shute and Towle found an intriguing interaction here: For those in the rule-induction group, spending a relatively high proportion of time exploring the computer environment (reading definitions, playing with the electricity simulation) paid off in better outcome scores (they learned more about electricity as determined by a posttest). For those in the rule-application group, on the other hand, they did much better on the posttest if they had spent minimal time looking up definitions and playing with the simulation. Interestingly, the rule-application group, on average, did better on the outcome test, but those in the rule-induction group outperformed 
those in the rule-application group if they engaged in a sufficient amount of exploratory behavior.

Given these kinds of results, Shute and Towle (2003) argue that e-learning, the name now given to instruction occurring with the aid of computers, will increase effectiveness insofar as it becomes adaptive, delivering the right instruction at the right "time, place, path, and pace." The essential concept that allows adaptivity, according to Shute and Towle, is the "learning object" (LO), which is a small instructional component-video, tutorial, demonstration, simulation, and so forth, that can be inserted into an instructional session as the teacher, or in this case, the teaching system, sees fit. The way this is done is by the teacher assessing the learner-both in a domain-dependent and domain-independent way.

Shute and Towle (2003) also review a specific system-Student Modeling Approach for Responsive Turoring (SMART) - which is capable of guiding the selection of learning objects to fit the immediate needs of the learner. SMART is a student modeling system that selects learning objects according to its estimate of how much a student knows and how fast a student is learning. It estimates learning speed based on two sources of a student's learning history. One source is how quickly a student is learning in the particular learning session. The approach of a computer reacting to this kind of information is called microadaptive. The other source is how quickly a student learns on average, or in general, not just in this session (e.g., based on how well a student performs on a separate learning task). The approach of a computer taking advantage of this kind of information is called macroadaptive. Combining microadaptive and macroadaptive approaches to estimate a student's current knowledge and learning speed, the SMART system selects appropriate learning objects for a particular learner at a particular moment in the instructional session. Shute and Towle express optimism that this kind of approach-regardless of the technicalities of how learning speed is estimated (they mention both regression and Bayesian inference methods) - shows promise for providing tailored instruction in an e-learning environment. Such instruction is designed to provide effective and engaging learning experiences.

\section{Woltz Article}

There were some general conclusions derived from Cronbach and Snow's (1977) handbook on aptitude-treatment interactions - that strong treatments benefited less able learners and that weaker treatments benefited more able learners (a finding that anticipated the now recognized scaffolding effect)—but the results were somewhat inconsistent, as Cronbach and Snow themselves admitted. One response to the inconsistency of findings was articulated by Cronbach (1975) in a 20-year follow-up to his original ATI article, entitled "Beyond the Two Disciplines of Scientific Psychology" and also known as the "hall of mirrors" article. In it, Cronbach argued that the possibilities of interactions were essentially endless-and be- cause of the statistical requirements for having to verify each of the many possible interactions, one ought to throw one's hands up in despair. Snow's response was perhaps more optimistic. He believed that searching for interactions between globally defined aptitudes such as "verbal ability" and treatments described as "the spatial treatment" would never suffice. What was needed was an articulation of what aptitudes meant at a process level and what instructional treatments demanded at a process level. This, with Office of Naval Research (ONR) sponsorship, led to the launching of Snow's Aptitude Research Project, in the late 1970s and 1980s, a program of research designed to do just that (see summary in Snow \& Lohman, 1984).

An excellent example of the kind of process analysis Snow had been pushing for can be found in the work of Dan Woltz (2003) and his colleagues and students over the past 2 decades at the University of Utah. In his article, Woltz describes how a detailed analysis of "implicit learning and memory processes" has yielded new ideas on the links between basic learning ability and performance on complex learning tasks. Woltz distinguishes between what he calls explicit and implicit cognitive processes. Explicit processes are the ones we are aware of (declarative, attention-driven), and implicit processes are those not available to conscious awareness (procedural, automatic). Consequently, most research has been done on explicit learning and memory processes, and only recently have we begun examining the importance of the implicit processes. Thus, Woltz argues that although much research on individual differences in cognition has focused on explicit processes, implicit processes represent potentially something different and worth exploring.

Woltz (2003) finds evidence for two kinds of implicit processes, each with predictive links to different kinds of cognitive tasks. One implicit process is called implicit learning. It is measured by "repetition priming" tasks in which the same item is given twice, and the score is how much improvement is shown the second time. Implicit learning predicts skill learning, such as learning new rules to solve problems. The other implicit process is called associative memory activation. It is measured by "semantic priming" tasks in which the item is not repeated, but the ideas invoked by the item are called on again, and the score is the benefit a person obtains from idea repetition. Associative memory activation, measured this way, predicts success on language tasks, such as reading.

In discussing the implications of these findings, Woltz (2003) points us to Snow's outline for a theory of aptitude and, in particular, suggests a possible ATI that could link low-level process analyses such as his with real-world learning. He discusses the acquisition-transfer trade-off, which is that a narrow task (e.g., learning one song on a piano to perfection) facilitates acquisition but hampers transfer (i.e., to other songs). He suggests that this trade-off could be accommodated by considering where in the acquisition sequence a narrow task (learning a single song) might optimally be broadened (introduce a new song or two) so as to achieve both 
fast acquisition and broad transfer. The key, he speculates, could be in considering an individual's implicit memory processes to identify the ideal point at which to switch from the narrow to the broader task- different individuals could have different optimal switching points.

\section{Lajoie Article}

Spatial tests and the spatial ability factor play a prominent role in studies of abilities and in theoretical abilities frameworks, such as Gustafsson's (1987) or Carroll's (1993). In many of his writings, Snow considered Gv, the spatial factor, to be on par in importance with the two other most prominent ability factors, general fluid ability (Gf) and general crystallized ability (Gc). At the same time, some of the most important admissions and selection test batteries, such as the Armed Services Vocational Aptitude Battery, Scholastic Assessment Test (SAT), and Graduate Record Exam (GRE) do not include spatial tests. Snow humorously suggested that this absence reflected the educational system's triumph in removing spatial abilities from its students in an imperialistic promotion of verbal skills. However, it could also reflect the fact that, with few exceptions, most criterion performances are primarily verbal as well.

A notable exception to this omission can be found in the engineering curriculum, where understanding spatial depictions, visualizing spatial relations, and imagining spatial transformations are highly valued skills and often spell the difference between academic success and failure. A task that embodies these skills is the standard orthographic projection task where one is asked to match two- and three-dimensional renderings of abstract objects. A detailed investigation of this task was the aim of Lajoie's (2003) article, which is based on her doctoral dissertation under Snow's supervision.

The orthographic projection task is one in which an observer is given a front and top, two-dimensional view of an object and is asked to construct or identify the third view or to describe what the object would look like in three dimensions. These are the standard mechanical, architectural drawings or assembly instructions we all have encountered at some point. In her first study, Lajoie (2003) presented this kind of task to experts and novices and asked them to talk through the process of constructing the missing side view of an object depicted by the front and top orthographic views. From these verbal protocols, Lajoie developed a model of how experts solve these problems and designed a computer-based learning environment to teach orthographic projection skill. It did this by showing the correspondence between two-dimensional line drawings and three-dimensional objects, as computers nicely do, teaching various spatial strategies, as well as providing feedback on drawing errors, and tailoring problem difficulty to students' skill level. Lajoie found that except for a few students performing highly at pretest, students receiving the approximately hour-long interactive computer tutorial showed a significant pre-post performance gain, suggesting the importance of the spatial process instruction on the orthographic projection task.

\section{CONCLUSION}

A fair criticism of psychology is that its theories do not generally outlast their creators. But influence is another matter, and Richard Snow has inspired many students and contemporaries to carry forward and expand on some of his most cherished beliefs, themes, and ideas, and we see evidence for that in this special issue. But beyond even the important themes, we observe Snow's influence in the professional values he conveyed and in the personal qualities he exuded. Snow was a tireless advocate of empiricism and quantification, showing appreciation for qualitative approaches, but as subordinate to quantitative ones. He believed in real-world applications, ever combining laboratory experiments with classroom studies. And he made it clear that the focus should be on the big issues-that one large, multivariate study could often be more beneficial to science and to practice than scores of little, univariate ones. But perhaps most important, Snow's personal enthusiasm, supportiveness, and respectfulness stimulated many to pursue research enabling greater understanding of individual learners attempting to achieve successful outcomes.

\section{ACKNOWLEDGMENT}

We thank David Lohman and Joan Talbert for comments and suggestions.

\section{REFERENCES}

Ackerman, P. L. (2003). Aptitude complexes and trait complexes. Educational Psychologist, 38, 85-93.

Carroll, J. B. (1993). Human cognitive abilities: A survey of factor-analytic studies. New York: Cambridge University Press.

Corno, L., Cronbach, L. J., Kupermintz, H., Lohman, D. F., Mandinach, E., Porteus, A. W., et al. (2002). Remaking the concept of aptitude: Extending the legacy of Richard E. Snow. Mahwah, NJ: Lawrence Erlbaum Associates, Inc.

Cronbach, L. J. (1975). Beyond the two disciplines of scientific psychology. American Psychologist, 30, 116-127.

Cronbach, L. J., \& Snow, R. E. (1977). Aptitudes and instructional methods: A handbook for research on interactions. Oxford, England: Irvington.

Gustafsson, J.-E. (1987). Hierarchical models of individual differences in cognitive abilities. In R. J. Sternberg (Ed.), Advances in the psychology of human intelligence (Vol. 4, pp. 35-71). Hillsdale, NJ: Lawrence Erlbaum Associates, Inc.

Lajoie, S. P. (2003). Individual differences in spatial ability: Developing technologies to increase strategy awareness and skills. Educational Psychologist, 38, 115-125.

Shute, V., \& Towle, B. (2003). Adaptive e-learning. Educational Psychologist, 38, 105-114.

Snow, R. E. (1977). Individual differences and institutional theory. Educational Researcher, 6, 11-15.

Snow, R. E., \& Lohman, D. F. (1984). Toward a theory of cognitive aptitude for learning from instruction. Journal of Educational Psychology, 76, $347-376$.

Woltz, D. J. (2003). Implicit cognitive processes as aptitudes for learning. Educational Psychologist, 38, 95-104. 